\title{
Minimal projected loss of blood donors with travel deferral
}

\section{Opinion}

Today we will be discussing projected blood donor loss if travel deferrals are implemented. Almost $20 \%$ of U.S. residents travel abroad each year. Acute viral infections like Chikungunya and dengue are common in much of the world. Dr. Hassan explains how a 14 or 28-day donor deferral period may help reduce transfusion transmitted infections:

i. The infections that we are focused on are acute viral infections with very short incubation periods, so that we think infected donors should be deferred using a 14-day to 28-day deferral.

ii. In order to estimate the potential loss in blood donations from a 14 or 28-day travel deferral period, investigators surveyed over 50,000 blood donors in the summer of 2014 and winter of 2015 .

Mr. Spencer et al. ${ }^{1}$ with the American Red Cross explains the study results:

i. We found that travel patterns were different in the winter than in the summer. The donor loss related to the travel associated deferral could range from $2-4 \%$ on an annual basis. If it were limited in scope such as a 14-day deferral for travel to the Caribbean and the Americas that donor loss might be approximately $0.4 \%$. If the deferral were crafted more broadly, then it might be as great as $4 \%$.

ii. Many of the viruses that could contaminate the blood supply are arthropod or mosquito-transmitted infections that have relatively short incubation and viremic periods. A 14 or 28day deferral period provides ample time for donors to develop an immune response and eliminate the virus before blood donation.

\author{
Volume 4 Issue 4 - 2017
}

\author{
Hassan Yousef \\ Department of blood transfusion medicine, University of \\ Medicine and Pharmacy of Craiova, Romania
}

\begin{abstract}
Correspondence: Hassan Yousef, consultant in blood transfusion, University of Medicine and Pharmacy of Craiova, Romania,EEmail dr_hassan_yousef@yahoo.com
\end{abstract}

Received: April 13, 2017| Published: May 04, 2017

Dr. Katz comments on how the deferral period could impact the blood supply:

i. I think that it is going to depend on where you are and how tight your blood supply might be. There are blood centers that are already using these sorts of deferrals and they have not had problems according to my conversations with their medical directors. That doesn't mean that everybody won't have trouble and that's why an understanding of the impact up front is paramount.

\section{Acknowledgements}

None.

\section{Conflict of interest}

The author declares no conflict of interest.

\section{References}

1. Spencer BR, Stramer S, Dodd R, et al. Abstract presentations from the AABB annual meeting anaheim. Transfusion. 2005;55(S3):3A-245A. 